\title{
A new genus and two new species of Pterostichini from China, with "sphodrine-like" parameres (Coleoptera, Carabidae)
}

\author{
Borislav Guéorguiev ${ }^{1}$, Riccardo Sciaky ${ }^{2}$ \\ 1 National Museum of Natural History, 1 Blvd. Tzar Osvoboditel, 1000 Sofia, Bulgaria \\ 2 Via Fiamma 13, 20129 Milano, Italy
}

http://zoobank.org/BDBF6376-4BCD-4269-9B79-7EF65B5778D2

Corresponding author: Borislav Guéorguiev (gueorguiev@nmnhs.com)

Received 23 June 2015

Accepted 12 August 2015

Published 3 September 2015

Academic editor:

James Liebherr

Key Words

\section{Carabidae}

Apophylon

taxonomy

China

Guizhou

Hunan

\begin{abstract}
A new genus of Pterostichini, Apophylon Guéorguiev \& Sciaky, gen. n. (type species: Apophylon schillhammeri Guéorguiev \& Sciaky, sp. n.) is proposed for Apophylon schillhammeri Guéorguiev \& Sciaky, sp. n. (type locality: China, SE Guizhou Province, Leishan County, SE Kaili) and Apophylon pangu Guéorguiev \& Sciaky, sp. n. (type locality: China, NW Hunan Province, Wulingyuan District, near the town of Wulingyuan). These two species share a unique combination of characters, not known in any other Pterostichini. The new genus can be distinguished by having (1) a left paramere without transverse apophysis; (2) a falcate right paramere, with styloid apex, broadened medial part and subbasal hasp; (3) a median lobe with dorsal ostium; (4) metatarsomeres 1-2 setose on the medioventral surface, in addition to the lateroventral setae; (5) meso- and metatarsomeres 1-4 with two dorsolateral grooves diverging distally; and (6) elytral striae with shining isodiametric microreticulation, which is in contrast to less shining transversemesh microreticulation on the elytral intervals.
\end{abstract}

\section{Introduction}

This paper describes a new genus and two new species of pterostichine beetles from China. As frequently occurs, especially in terms of individual collections from little investigated areas, one species is described upon a single male specimen. As these species have been rarely collected in the past, we do not anticipate additional specimens to be available for study in the near future. The uniqueness of these beetles persuaded us to describe these species with a hope that this will encourage more investigations in the region.

The first author visited the Naturhistorisches Museum Wien, Vienna in 2011 borrowing a small collection of unidentified carabids. Among those was a single male specimen with a habitus rather unusual for a Pterostichini found in the region. The examination of the genitalia and various characters revealed a species with retained primitive features of the median lobe of the aedeagus and parameres. The combination of characters states are evidence that the specimen in question belongs to a new species and is both generically distinctive and systematically isolated from all other pterostichines. Some years earlier, four adult specimens similar to the above specimen had been borrowed for study from the NMW by the second author. These specimens had only been partly studied since they were teneral and very fragile. The subsequent study and comparison of these five specimens showed that they belong to two related species from a peculiar lineage of the tribe Pterostichini. The following character states: 1/ mandibular scrobe without seta; $2 /$ basal bulb of the aedeagus closed dorsally; 3 / parameres unsetose and dissimilar in shape, left paramere conchoid; 4/ frons with two supraorbital setae; 5/ antennae filiform, with segments 1-3 without pubescence; 6/ labial palpomere 2 with two median setae; $7 /$ apicolateral elytral 
plica present, externally visible; and 8/ elytron with parascutellar pore inside base of second stria, determine the inclusion of the new taxa into this tribe.

\section{Materials and methods}

Measurements were made with a calibrated ocular micrometer mounted on a stereoscopic binocular Olympus SZX10 microscope. Photos were taken with a Zeiss Stemi 2000 microscope equipped with an AxioCam ERc 5s camera and were stacked using the free software CombineZM of Alan Hadley (version 26 April 2008). Drawings were made using a Zeiss transmitted-light microscope.

Measurements: body length from the apex of the longer mandible in closed position to the apex of the longer elytron (BL); body width as maximum distance across the widest point of elytra (BW); linear distance from apex of longer mandibular to the imaginary line connecting the posterior end of tempora (HL); maximum linear distance across the head, including the eyes (HW); length of pronotum, measured along the midline, from the apical margin to the basal margin (PL); maximum width of pronotum (PW); width of the pronotal apex, between the tips of the fore angles $(\mathrm{PaW})$; width of the pronotal base, between the tips of the hind angles $(\mathrm{PbW})$; length of elytra, from the basis of scutellum to the apex of the longer elytron (EL); maximum width of elytra (EW).

The examined material is deposited in the following collections:

NMNHS National Museum of Natural History, Sofia (Borislav Guéorguiev)

NMW Naturhistorisches Museum Wien, Vienna, Austria (Harald Schillhammer)

cRS collection Riccardo Sciaky, Milano, Italy

For naming the units of the female genital tract, we follow the scheme used by Liebherr and Will (1998) and borrow some terms from Ball and Shpeley (2013). The distribution map was made using the online mapping software SimpleMappr (CDavid P. Shorthouse)

\section{Taxonomy}

\section{PTEROSTICHINI Bonelli, 1810}

Diagnosis. Integument glabrous; frons usually with two pair of supraorbital setae (one seta in Haptotapinus Reitter, 1886, Haptoderotapinus Jedlička, 1930 and Unitrichus Sciaky, 1997, three or more setae in Rambousekiella Knirsch, 1925 and Ethira Andrewes, 1936); mandibular scrobe without seta; antennae filiform, antennomeres 1-3 glabrous (antennomere 3 pubescent in Molops Bonelli, 1810, Rambousekiella Knirsch, 1925, and a few West Mediterranean genera), scape attached to pedicel centrically; penultimate labial palpomere usually with two median setae, without apical setae (2-5 median setae and 1-3 apical setae in some species of Cyclotrachelus Chaudoir, 1838, cfr. Bousquet 1999: 195, 1-5 apical setae in Steropanus Fairmaire, 1888); pronotum usually with one anterolateral and one posterolateral seta (two or more anterolateral setae in Parapterostichus Desbrochers des Loges, 1906 and Ethira Andrewes, 1936, posterior setae absent in Tapinopterus Schaum, 1858, Speluncarius Reitter, 1886 and Neostomis Bousquet, 1983); procoxal cavities uniperforated and closed; mesocoxal cavities conjunct (mesepimeron does not reach the middle coxal cavity); metepisternum separated from metepimeron by distinct suture, laterally not coadunate with elytral epipleuron; elytron with parascutellar pore (if present) near or inside base of the second stria and apicolateral plica (secondarily lost in several groups); protibia with outer apical angle not produced; posterior margin of mesofemur with at least two long setae; metacoxa usually with two lateral setae (a third seta at medial position in Cryobius Chaudoir, 1838, Tapinopterus Schaum, 1858, Speluncarius Reitter, 1886, Rambousekiella Knirsch, 1925 and Pseudorambousekiella Schweiger, 1967); claws smooth; median lobe of aedeagus tube-like, with basal bulb closed dorsally; parameres without setae, the left paramere mostly conchoid; gonocoxal rami absent.

The lack of synapomorphies, in either adult or larval stages, yet discovered to suggest that the tribe (about 2500 species) forms a monophyletic lineage, arrives at the conclusion that it is an evolutionary grade (Bousquet 2012).

\section{Apophylon Guéorguiev \& Sciaky, gen. n.}

http://zoobank.org/15484C26-BD49-4303-8232-D877C8DACEEF

Type species. Apophylon schillhammeri sp. n.

Diagnosis. The following combination of morphological features distinguishes this taxon from all the other Pterostichini known to date:

1) mentum transverse, weakly emarginate;

2) pronotal basal impressions, lateral margins and basal part of midline, as well as the elytral striae both grooved and widened;

3) elytral microreticulation double, isodiametric within the striae, transverse-mesh on the intervals;

4) apicolateral plica of elytron large and visible;

5) parascutellar striola absent, i.e. striola anastomosing in full with stria 1 ;

6) angular base of stria 1 absent;

7) stria 7 shallow (punctiform) in anterior half;

8) parascutellar setiferous punctures present at base of stria 2;

9) no discal setiferous punctures in interval 3;

10) remnants of both stria 9 and interval 10 present along penultimate fifth of elytron;

11) meso- and metatarsomeres 1-4 with two dorsolateral grooves divergent distally; 
12) metatarsomeres 1-2 (and sometimes metatarsomere 3 ) setose on medioventral surface, in addition to the lateroventral setae;

13) tarsomere 4 moderately emarginate along apical margin in all legs;

14) abdominal sternite 6 bisinuate and bordered along apical margin in both sexes, flat and smooth in males, impressed and rugose on apical part in females.

15) median lobe of aedeagus with dorsal ostium;

16) left paramere without transverse apophysis;

17) right paramere falcate, with styloid apex, medial part broadened and hasp situated at subbasal position;

18) laterotergite and basal gonocoxite 1 both with trichoid setae;

19) apical gonocoxite narrowed distally, with apex widely rounded, two ensiform setae, two nematiform setae, and a lots of pit pegs on dorsal and ventral surfaces.

Description. Habitus. Size medium (ca. 12.5-13.5 $\mathrm{mm}$ ) for Oriental Pterostichini, shape elongate, subparallel (Figs 1, 11). Tegument. Glabrous throughout (excl. antennomeres 4-11), dorsally smooth; sternal parts partly punctate, namely postgenae, proepisterna, mesosternum and mesosterna, gula of head, prosternum and proepipleura impunctate, abdomen mostly impunctate, slightly wrinkled laterally. Color. Body dark brown to black on dorsal and ventral surface, antennae, palpomeres and legs red-brown to black. Microsculpture. Present (A. pangu) or largely reduced (A. schillhammeri); striae of elytra with shiny isodiametric microreticulation, in contrast to less shiny, transverse-mesh microreticulation on elytral intervals. Head. Eyes large, laterally protruding, tempora minute; frons with two well-developed and relatively deep furrows, divergent backward, reaching anterior supraorbital punctures; two pairs of supraorbital punctures, anterior puncture just before middle of eye, posterior one at posterior fifth of eye; antennae long, filiform, with segments 1-3 and basal fifth of segment 4 glabrous, pubescent from antennomere 4, scape shorter than antennomere 3, with single dorsal seta distally, pedicel with one ventral seta, not eccentrically attached to scape, segment 3 with six apical setae, end of antennomere 8 and antennomeres 9-11 exceeding posterior margin of pronotum; labrum subrectangular, with anterior margin concave in middle and six equidistant setae, middle four shorter than lateral two; clypeus subtrapezoid, with anterior margin straight and with two punctures removed from anterior margin at distance of one and a half diameters of puncture and closer to lateral margins than to anterior margin; mandibles large, elongate, more or less pointed and hooked at apex; maxillae shorter than mandibles, stipes with two long lateroventral setae; ligula with two setae, paraglossae long, glabrous (Fig. 3); labial palpomeres elongate, fusiform, with penultimate segment bisetose; maxillary palpi considerably longer than labial palpi, with glabrous and elongate segments; labium with dis- tinct suture between mentum and submentum, mentum transverse, weakly emarginate, sides of sinus widely divergent, epilobes narrow, median tooth large, weakly emarginate, slightly bifid in front, bordered posteriorly, labial setae long, paramedial pits indistinct; submentum with two medial setae, without lateral setae (Fig. 3). Thorax. Pronotum subcordate, wider than long, widest before middle; midline narrow anteriorly and wide posteriorly, not reaching anterior and posterior borders; anterotransverse sulcus superficial; two basal impressions, linear, wide, deep, and divergent to base; anterior border slightly narrower than basal border, concave medially, finely rimmed laterally, rim obliterated medially; sides rounded anteriorly, sinuate before posterior angles, with wide and grooved lateral margin from each side; basal border slightly convex, oblique towards angles, not rimmed; anterior angles rounded, hardly protruding; posterior angles distinct, obtuse, slightly outward protruded; anterolateral and posterolateral setiferous punctures present. Elytra elongate, not fused, widest after middle, with slightly convex disc and subapical sinuation; apicolateral plica present, large and visible from above and at sides; basal border complete, touching stria 1; shoulders completely rounded, without denticles; striae wide, deep, impunctate; stria 7 shallow along anterior half of elytron, with one or two preapical setiferous punctures (posterior one closer to apex of elytron than to suture) (Figs 4, 13); stria 9 present along penultimate fifth of elytron; parascutellar striola anastomosing with stria 1, angular base of stria 1 absent; intervals smooth, 7-8 almost fused anteriorly; interval 9 beginning from umbilicate puncture III, not reaching apex; interval 10 present at penultimate fifth of elytron; parascutellar setiferous punctures present, small, situated at base of stria 2; no discal setae in interval 3; umbilicate series mostly with 16 pores (sometimes 15, 17 , or 18), indistinctly divided into humeral and apical groups by an interruption between pores VII and VIII, interruption as long as double distance between pores VI and VII, humeral group of seven pores, I-III situated before beginning of interval 8 , IV-VII within stria 8 , III larger than rest, apical group of nine pores, all within stria 8 , pores XI and XVI larger than others. Hind wings present. Prosternum smooth, prosternal process unbordered, proepipleura broadened posteriorly. Metasternum smooth, mostly impunctate, finely punctate only laterally, metepisterna finely punctate, twice longer than wide, strongly narrowed posteriorly. Legs moderately long and slender; procoxa without seta; mesocoxa with one lateral and one medial seta; metacoxa with two lateral setae, one anterolateral and one posterolateral seta, without medial seta, with metacoxal sulcus arcuate and ended before lateral end of coxa; protrochanter with one anterior seta at distal position; mesotrochanter with one posterior seta at distal position; metatrochanter without seta (but one female paratype of $A$. pang $u$ with a seta at proximal position on left metatrochanter); profemur with three long setae on posterior surface, one proximal, one medioventral and one distal seta; mesofemur with three long setae 
on anterior surface, two closely situated proximal setae and one medioventral seta; metafemur with two long setae on anterior surface, one proximal seta and one medioventral seta; protibia rather dilated distally in both sexes, with two long clip setae; mesotibia nearly as long as mesofemur, with ventral ctenidium well differentiated; metatibia longer than metafemur; all tarsomeres dorsally glabrous (only tarsomere 5 with a pair of subapical setae), with two rows of lateroventral setae, glabrous on medioventral surface, except for metatarsomeres 1-2 (and sometimes metatarsomere 3) which are setose also medioventrally (Fig. 5), tarsomere 4 with apical emargination from above in all legs, meso- and metatarsomeres 1-4 with two dorsolateral grooves, posteriorly divergent (Fig. 6); male protarsomeres 1-3 strongly and symmetrically expanded, biseriate squamose beneath, segment 1 and 2 nearly equal in width, segment 3 flatter and narrower than previous two; tarsal claws smooth, one seta at base of each tarsal claw. Abdomen. Sternites 3-5 each with a pair of ambulatory setae, sternites 4-6 without transverse sulci, terminal sternite 6 in both sexes bisinuate and bordered marginally, in males flat and smooth with two large terminal setiferous punctures (Fig. 7), in females apically impressed and rugose, with four terminal setiferous punctures (Fig. 17). Male genitalia: aedeagus (Figs 8-10, 14-16). Median lobe of aedeagus long, in lateral view strongly arcuate ventrally, with basal bulb large and well developed, basal orifice concave, medial part narrower than bulb, apical lamella slightly bent ventrally; median lobe dorsally elongate, slightly bent to right apically, with left margin straight to slightly concave and right margin convex, apical lamella somewhat narrowed before tip, thereupon widened, subapical orifice (ostium) on dorsal side, elongate, extended over entire dorsum; inner sac of aedeagus with or without chitinized structures, with complex membranous pattern distally. Left paramere conchoid, without transverse apophysis, with small apical denticle on ventral margin. Right paramere falcate, attenuate at apex, broadened medially, with a hasp situated at subbasal position. Female genitalia (Figs 19-21), consisting of bipartite laterotergits and gonocoxae (latter clearly separated into basal gonocoxite 1 and apical gonocoxite 2). Laterotergite subtriangular, articulated to lateral base of gonocoxite 1, with protruding apophysis on anterior margin and 10-12 trichoid setae on posterior margin medially; gonocoxite 1 relatively narrow, elongate, with several long trichoid setae on ventral surface laterodistally; gonocoxite 2 not curved, with sides narrowed distally, apex not tapering, but widely rounded, two broad ensiform setae, one dorsomedial and one dorsolateral, preapical sensory furrow on ventral surface, with a furrow peg bearing two long and thin nematiform setae, and numerous pit pegs on both surfaces.

Etymology. Apophylon is a compound word, based on the Greek prefix $\dot{\alpha} \pi$ ó [apó] (away from, separate) and $\varphi v ́-$ hov [fýlon] (tribe, clan), alluding to the putative systematic remoteness of this taxon concerning its relatives. It is treated as a Greek neuter.
Apophylon schillhammeri Guéorguiev \& Sciaky, sp. n.

http://zoobank.org/A13E950C-2BAC-43F4-A332-72A1FED0171A

Figs 1-10

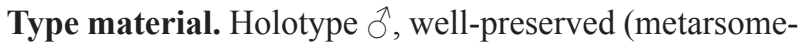
res 3 and 5 of the left hind leg were lost after taking Fig. 1), “CHINA, Guizhou, Leishan Co. SE Kali, NE Leishan Leigong Shan, E - slope $26^{\circ} 23.07^{\prime} \mathrm{N} 108^{\circ} 13.03^{\prime}$ 'E” ' [printed, white] / "above Fangxiang vill. Nanmang riv., $900 \mathrm{~m}$ 16.6.2001, leg. Wang \& Schillhammer (10)" [printed, white] / "HOLOTYPE Apophylon gen. nov. schillhammeri sp. nov. Guéorguiev \& Sciaky des. 2015" [printed, red]. The holotype is preserved in NMW. The genitalia of the holotype are preserved in glycerine inside a plastic vial pinned under the card on which the specimen is mounted.

Diagnosis. See Table 1.

Description (based on male only). Habitus (Fig.1). Elongate, subparallel, moderately convex. Tegument. Dorsally smooth, largely impunctate, only head in frontal furrows and vertex laterally, as well as pronotum base between impressions coarsely punctate. Measurements and ratios. See Table 2. Color. Body anthracite black dorsally and ventrally, antennomeres 2-11, palpomeres and tarsomeres dark red to fire brick red. Microsculpture. Chiefly reduced (not visible); isodiametric on pronotal lateral margins and basal impressions, elytral basal border and striae, transverse-mesh on labrum and abdominal sterna in middle. Lustre. Dorsal and ventral surfaces moderately shiny, prosternal process, metasternum, and abdominal sterna shinier medially. Head (Fig. 2). Longer than wide, slightly narrower than pronotum; disc smooth; eyes as long as 1.2 times length of antennomere 3 , tempora minute, ca. $1 / 5$ of length of eye; frontal furrows wide, deep, roughly and coarsely punctate on inside and marginally; vertex with some large, scattered punctures on each side; clypeal suture partly obliterated; mandibles lightly pointed and hooked at apex. Thorax. Pronotal disc slightly convex, mostly smooth, only internal margin at each basal impression with a few coarse punctures; anterior angles rounded, hardly protruded; posterior angles obtuse, slightly protruded outside (Fig. 2). Elytra elongate, with sides narrowed towards base, widened towards apex; shoulders completely rounded; striae well-impressed, both grooved and wide; stria 7 with one preapical setiferous puncture (Fig. 4); intervals impunctate, smooth, 1-3 flat over most extent, 4-9 subconvex; intervals 2 and 8 fused apically; single apical puncture on lateral margin behind both end of stria 7 and junction of intervals 2 and 8 (Fig. 4); umbilicate series with 16 pores on left elytron and 18 pores on right elytron, humeral group of seven pores on both elytra, apical group consists of nine pores on left elytron and eleven pores on right elytron. Hind wings present. Prosternal process with posterior margin rounded. Legs moderately long and slender; metatarsomeres 1-2 setose medioventrally, in addition to lateroventral setae. Abdomen. Terminal sternite 6 distinctly sinuate and bordered on ex- 


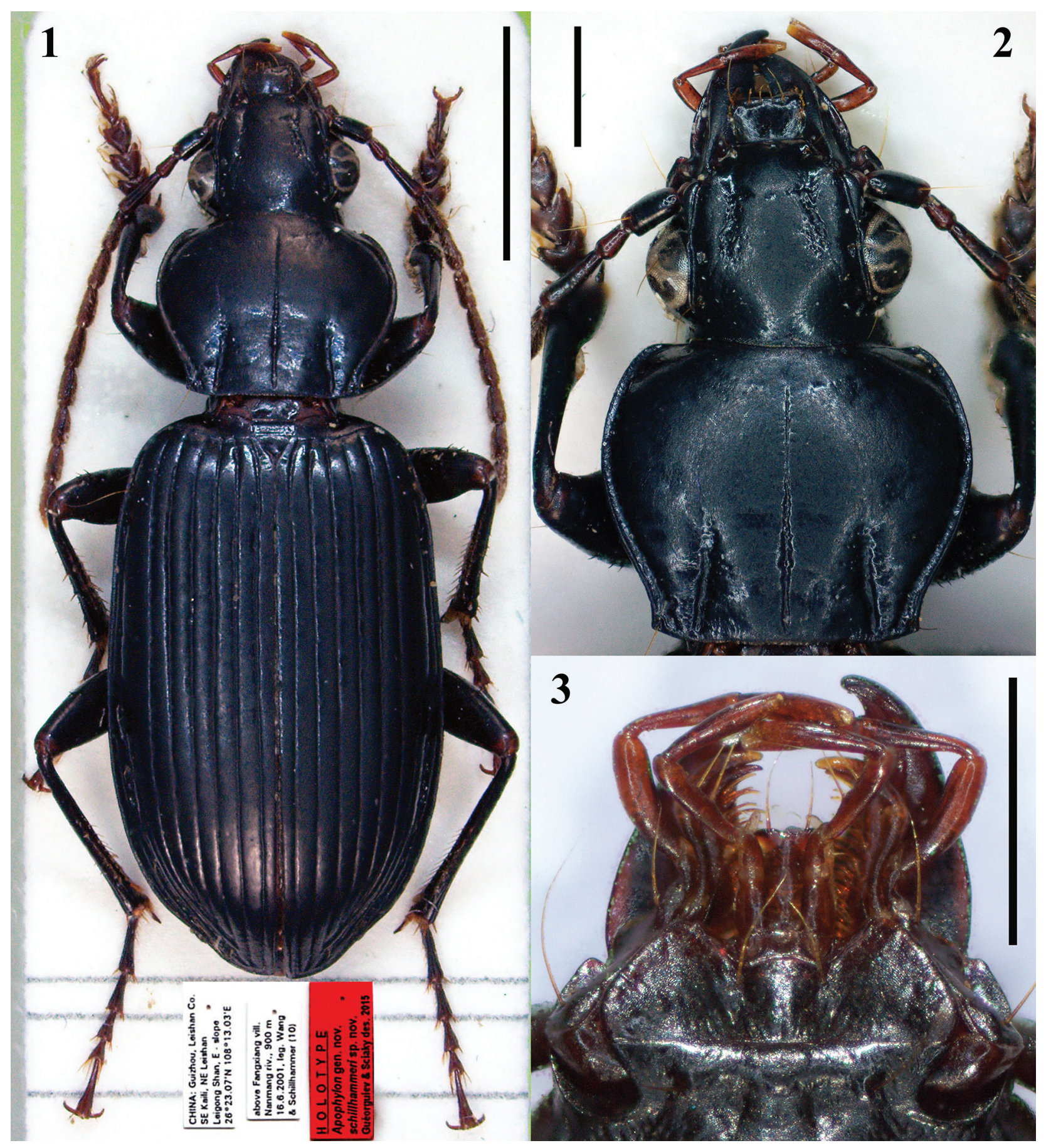

Figures 1-3. Apophylon gen. n. schillhammeri sp. n. from vil. Fangxiang, Guizhou, China, holotype. 1 Habitus; 2 Head and pronotum; 3 Head, ventral part of mouthparts. Scale lines: 3 mm (Fig. 1); 1 mm (Figs 2-3).

ternal margin, with two large marginal punctures (Fig. 7). Male genitalia (Figs 8-10). Median lobe of aedeagus long, ventrally bent at an angle of nearly $90^{\circ}$, dorsally slightly curved to right apically, with apical lamella narrowed before tip, thereupon widened, subquadrate at tip, with a left-sided lobe prominent. Inner sac of aedeagus with a submedial lamella transversely situated, large and well chitinized. Left paramere conchoid, without transverse apophysis, with apical denticle on ventral margin (Figs 8-9, c-d). Right paramere falcate, with apical part protracted, medial part moderately broadened and a hasp at subbasal position (Figs 8-9, b, e).

Etymology. A noun in the genitive case for the collector of the holotype of this new species, the prominent specialist of Staphylinidae Harald Schillhammer.

Type locality and habitat. Harald Schillhammer (personal communication) kindly provided us detailed description for the site and time when the holotype of $A$. schillhammeri sp. n. was collected: "9) SE Kaili, Leishan Co., NE Leishan, E - slope of Leigong Shan, 26²6.59’ N, 
Table 1. Diagnostic features of Apophylon species.

\begin{tabular}{|c|c|c|}
\hline Diagnostic feature & A. schillhammeri sp. $\mathrm{n}$. & A. pangu sp. n. \\
\hline \multicolumn{3}{|l|}{ A. Morphological features } \\
\hline $\mathrm{EL} / \mathrm{EW}$ & 1.64 & $1.73-1.80$ \\
\hline $\mathrm{EL} / \mathrm{PL}$ & 2.88 & $2.98-3.18$ \\
\hline punctuation of tegument dorsally & $\begin{array}{l}\text { largely impunctate (excl. head and base of } \\
\text { pronotum) }\end{array}$ & largely with micropunctures \\
\hline microsculpture dorsally & $\begin{array}{l}\text { mostly reduced, distinct only on labrum, } \\
\text { pronotum basal impressions and lateral } \\
\text { margins, elytral basal border and striae }\end{array}$ & developed, distinct on head, pronotum and elytra \\
\hline frontal furrows on head & wide, coarsely punctate (Fig. 2) & narrow, with micropunctures (Fig. 12) \\
\hline vertex of head laterally & with several large punctures (Fig. 2) & with micropunctures (Fig. 12) \\
\hline clypeal suture & partly obliterated (Fig. 2) & present, fine (Fig. 12) \\
\hline $\begin{array}{l}\text { punctuation of the pronotum basis, } \\
\text { between the impressions }\end{array}$ & $\begin{array}{l}\text { internal margin of each impression with a } \\
\text { few coarse punctures (Fig. 2) }\end{array}$ & $\begin{array}{l}\text { whole area with micropunctures and several longitudinal wrinkles } \\
\text { (Fig. 12) }\end{array}$ \\
\hline elytral intervals $1-3$ anteriorly & flat & subconvex \\
\hline elytral intervals 2 and 8 & fused apically (Fig. 4) & divided apically by stria 7 (Fig. 13) \\
\hline setiferous punctures within stria 7 & one (Fig. 4) & two, as apical one on very end of stria (Fig. 13) \\
\hline prosternal process posterior margin & rounded & nearly straight \\
\hline median lobe of aedeagus in lateral view & more arcuate ventrally (Figs 8-9) & less arcuate ventrally (Figs 14-15) \\
\hline apical lamella of aedeagus in dorsal view & $\begin{array}{l}\text { subquadrate at tip, with a left sided lobe } \\
\text { (Fig. 10) }\end{array}$ & nearly rounded at tip, without prominent lobe (Fig. 16) \\
\hline internal sac of aedeagus & with a large, well chitinized lamella (Fig. 10) & without lamella (Fig. 16) \\
\hline right paramere & $\begin{array}{l}\text { more attenuate apically, moderately } \\
\text { broadened medially (Figs 8-9) }\end{array}$ & shortly attenuate apically, strongly broadened medially (Figs 14-15) \\
\hline \multicolumn{3}{|l|}{ B. Geographical features } \\
\hline Area of distribution (river valley) & $\begin{array}{c}\text { Yuan River Watershed: upper Qingshui River } \\
\text { Basin (Fig. 22) }\end{array}$ & Lishui River Watershed: Suoxi River Basin (Fig. 22) \\
\hline
\end{tabular}

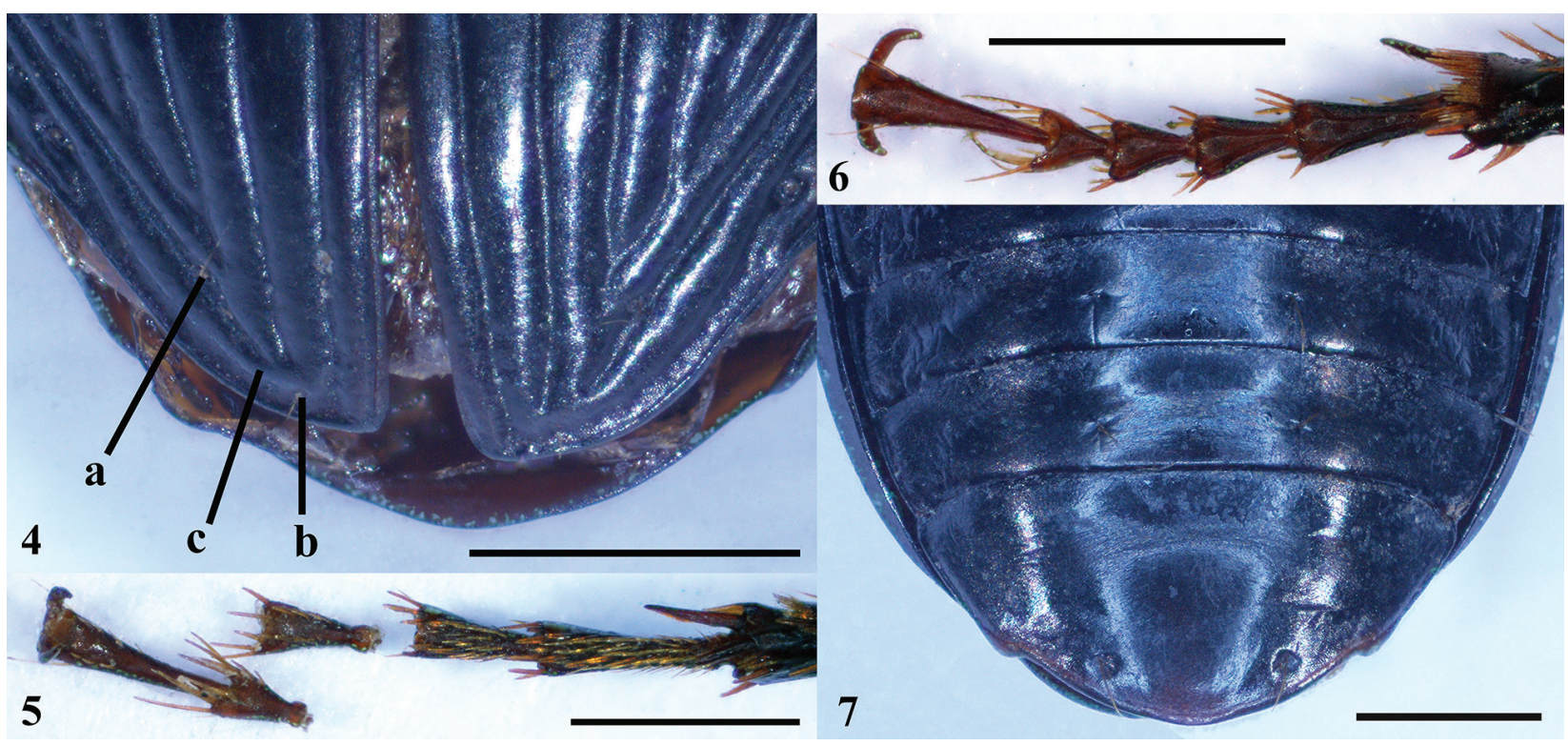

Figures 4-7. Apophylon gen. n. schillhammeri sp. n. from vil. Fangxiang, Guizhou, China, holotype. 4 Apex of elytra (a preapical puncture in stria 7; b apical setiferous puncture behind end of stria 7; c fused intervals 2 and 8); 5 Left metatarsus, ventral view; 6 Right mesotarsus, dorsal view; 7 Abdominal sternites 4-6, ventral view. Scale lines: 1 mm (Figs 4-7).

$108^{\circ} 16.53^{\prime} \mathrm{E}$, ca. $900 \mathrm{~m}$, Nanmang river at and above Fangxiang village, ca. 15-20 m wide, variably fast flowing, slightly polluted by surrounding farmland. 16.6.2001, leg. Schillhammer \& Wang; 10) as 9), gravel banks, largesized stones (up to $50 \mathrm{~cm}$ diameter), with interstitial of fine sand and clay. 16.6.2001, leg. Schillhammer \& Wang”.
According to this information, the correct GPS coordinates of the type locality are $26^{\circ} 26.59^{\prime} \mathrm{N}, 108^{\circ} 16.53^{\prime} \mathrm{E}$, which differ from the data written on the label pinned under the specimen (see "Type material"). In reality, it was an error in the process of printing the labels (Harald Schillhammer, personal communication). 

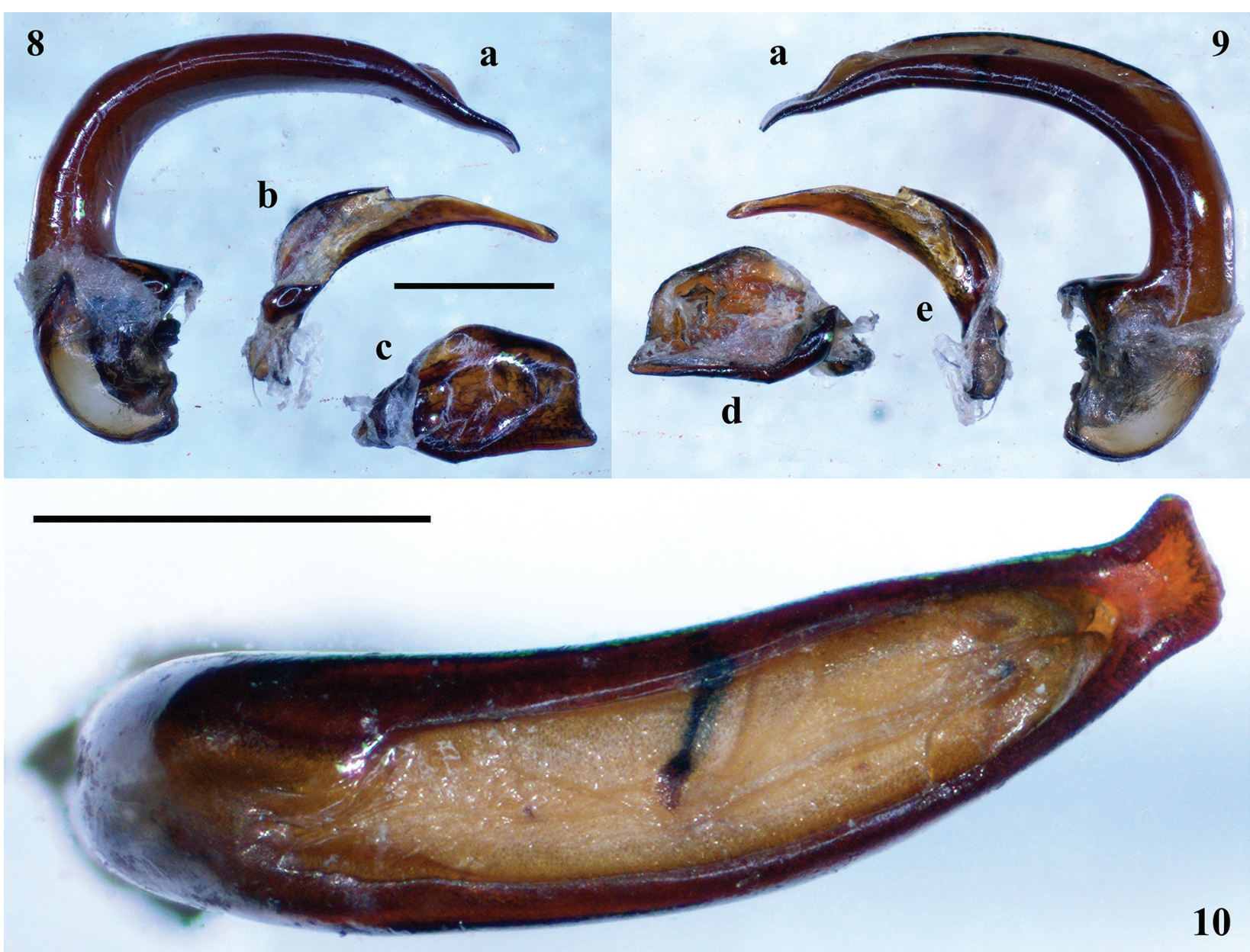

Figures 8-10. Apophylon gen. n. schillhammeri sp. n. from vil. Fangxiang, Guizhou, China, holotype. 8-10. Aedeagus (8 left lateral view; 9 right lateral view; 10 dorsal view; a median lobe; $\mathbf{b}$ right paramere, internal face; $\mathbf{c}$ left paramere, external face; $\mathbf{d}$ left paramere, internal face; e right paramere, external face). Scale lines: $1 \mathrm{~mm}$ (Figs 4-10).

Table 2. Data about variation in measurements and ratios among the species of Apophylon gen. $\mathrm{n}$.

\begin{tabular}{c|c|c|c|c|c|c|c}
\hline Measurement and ratios & A. schillhammeri sp. n. & \multicolumn{5}{c}{ A. pangu sp. n. } \\
\hline & $\mathrm{HT} \hat{\gamma}$ & $\mathrm{HT} \hat{\gamma}$ & $1 \mathrm{PT}+$ & $2 \mathrm{PT}+$ & $3 \mathrm{PT}+$ & range & mean \\
\hline $\mathrm{BL}(\mathrm{mm})$ & 12.6 & 13.1 & 13.8 & 13.1 & 13.8 & $13.1-13.8$ & 13.45 \\
\hline $\mathrm{BW}(\mathrm{mm})$ & 4.4 & 4.4 & 4.5 & 4.4 & 4.4 & $4.4-4.5$ & 4.43 \\
\hline $\mathrm{PW} / \mathrm{HW}$ & 1.37 & 1.39 & 1.4 & 1.45 & 1.38 & $1.38-1.45$ & 1.41 \\
\hline $\mathrm{PW} / \mathrm{PL}$ & 1.29 & 1.25 & 1.26 & 1.29 & 1.25 & $1.25-1.29$ & 1.26 \\
\hline $\mathrm{PW} / \mathrm{PaW}$ & 1.47 & 1.49 & 1.43 & 1.47 & 1.38 & $1.38-1.49$ & 1.44 \\
\hline $\mathrm{PW} / \mathrm{PbW}$ & 1.4 & 1.42 & 1.37 & 1.43 & 1.38 & $1.37-1.43$ & 1.4 \\
\hline $\mathrm{PbW} / \mathrm{PaW}$ & 1.05 & 1.05 & 1.04 & 1.02 & 1 & $1.00-1.05$ & 1.03 \\
\hline $\mathrm{EL} / \mathrm{EW}$ & 1.64 & 1.73 & 1.8 & 1.77 & 1.77 & $1.73-1.80$ & 1.77 \\
\hline $\mathrm{EL} / \mathrm{PL}$ & 2.88 & 2.98 & 3.06 & 3.18 & 3.08 & $2.98-3.18$ & 3.08 \\
\hline $\mathrm{EW} / \mathrm{PW}$ & 1.4 & 1.38 & 1.34 & 1.4 & 1.38 & $1.34-1.40$ & 1.38 \\
\hline
\end{tabular}

The small river of Nanmang flows into the upper part of the basin of the Qingshui River. The Qingshui enters the Yuan River, which is one of the main tributaries of the Yangtze River in Hunan. Most probably, the species is a hygrophilous upland dweller that lives adjacent to water. Administratively, the type locality is in Leishan County, Qiandongnan Miao and Dong Autonomous Prefecture, south-eastern part of Guizhou Province, China (Fig. 22).

\section{Apophylon pangu Guéorguiev \& Sciaky, sp. n.}

http://zoobank.org/0A24BF2E-E805-45DF-9FDF-6EF9FC1A1FE5 Figs 11-21

Type material. Holotype $\hat{\delta}$, well-preserved, no part missing, "CHINA, NW-Hunan 1993 Wulingyuan, N Dayong Zangjiajie, 30.10., 450m leg. Schillhammer (4)" [printed, white] / "HOLOTYPE Apophylon gen. nov. 


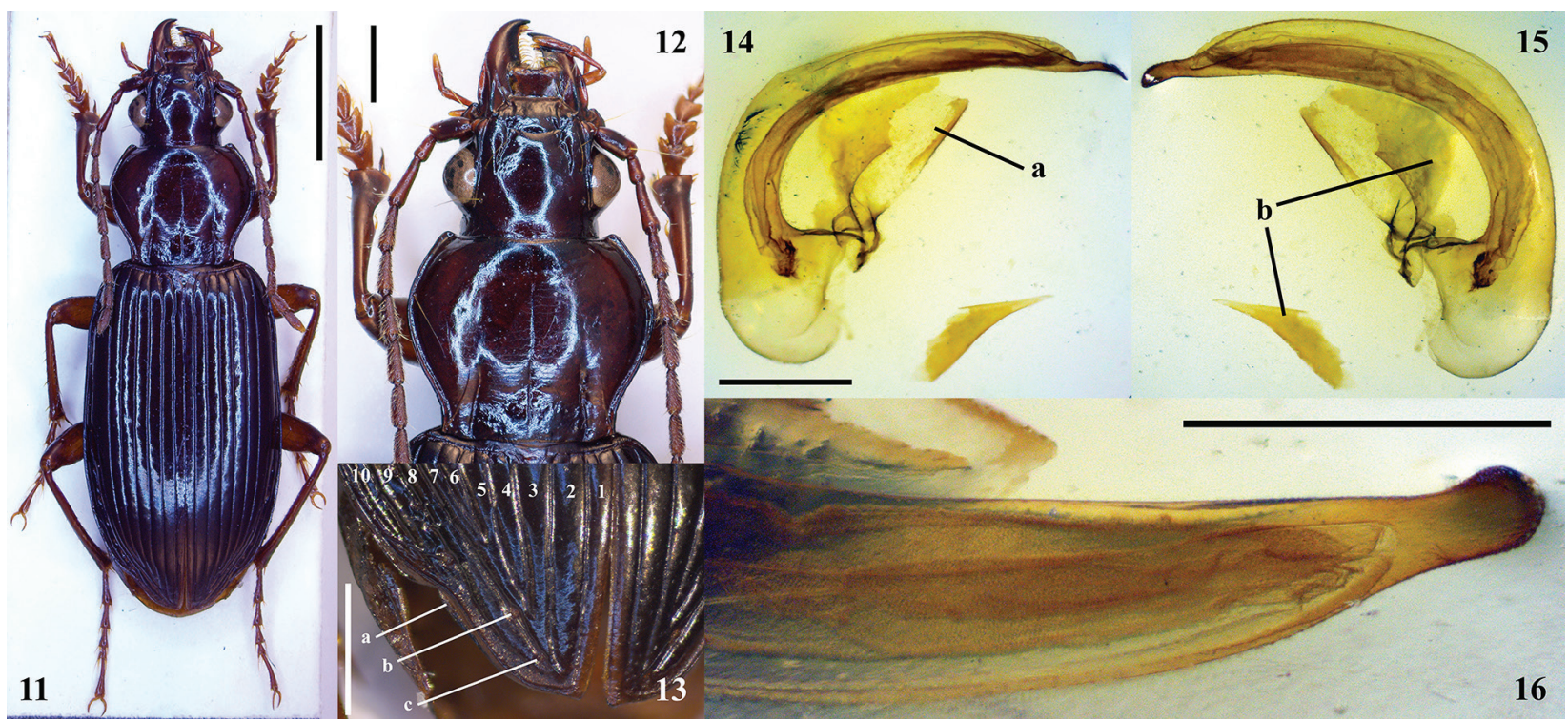

Figures 11-16. Apophylon gen. n. pangu sp. n. from Zhangjiajie national Forest Park, Hunan, China, holotype. 11 Habitus; 12 Head and pronotum; 13 Apex of left elytron (a apicolateral plica; $\mathbf{b}$ preapical puncture in stria 7; $\mathbf{c}$ apical setiferous puncture at end of stria 7; 1-10 numeration of intervals); 14-16. Aedeagus with attached parameres (14 left lateral view; 15 right lateral view; 16 dorsal view; a left paramere; b right paramere). Scale lines: $3 \mathrm{~mm}$ (Fig. 11); $1 \mathrm{~mm}$ (Figs 12-16).

pangu sp. nov. Guéorguiev \& Sciaky des. 2015" [printed, red]. Paratypes $3+$ 우, each one supplied with a first label as that of the holotype, and with a second label: "PARATYPE Apophylon gen. nov. pangu sp. nov. Guéorguiev \& Sciaky des. 2015" [printed, red]. The holotype and one paratype are preserved in NMW, while the other two paratypes are deposited in NMNHS and cRS, respectivelly. The genitalia of the holotype are preserved in Euparal on a separate piece of plastic pinned under the card on which the specimen is mounted.

Diagnosis. See Table 1.

Description. Habitus (Fig. 11). Elongate, subparallel, slightly convex. Tegument. Dorsally smooth, but head, pronotum and elytra with micropunctures visible at higher magnification. Measurements and ratios. See Table 2. Color. Body rufous to black dorsally and ventraly, antennomeres 2-11, palpomeres and tarsomeres lighter. $\mathrm{Mi}$ crosculpture. Isodiametric to slightly transverse-mesh on head and pronotum, distinctly transverse-mesh on elytra and abdominal sterna. Lustre. Body throughout moderately shiny. Head (Fig. 12). Longer than wide, narrower than pronotum; disc moderately convex; eyes as long as 1.1 times length of antennomere 3 , tempora minute, ca. $1 / 4$ of length of eye; frontal furrows narrow, with micropunctures; vertex without large punctures; clypeal suture present, fine; mandibles pointed and hooked at apex. Thorax. Pronotal disc slightly convex, with micropunctation throughout and several longitudinal wrinkles between basal impressions; anterior angles rounded, slightly protruded; posterior angles obtuse, slightly protruded outside (Fig. 12). Elytra with sides narrowed towards base, widened towards apex; shoulders completely rounded; striae well-impressed, wide and somewhat grooved; stria 7 with two setiferous punctures, a larger preapical and a smaller apical, as latter on very end of stria (Fig. 13); intervals smooth, with scattered micropunctation, subconvex; intervals 2 and 8 divided apically by stria 7; umbilicate series mostly with 16 pores (sometimes 15 or 17), humeral group of seven pores, apical group of nine pores. Hind wings present. Prosternal process with posterior margin nearly straight. Legs moderately long and slender; metatarsomeres $1-2$, and sometimes metatarsomere 3 , setose medioventrally, in addition to lateroventral setae. Abdomen. Sternite 6 in both sexes bisinuate and bordered marginally, in males flat and smooth with two large marginal setiferous punctures, in females impressed and rugose apically with four punctures (Fig. 17); postabdominal sternite 7 of female short, consisting of two chitinized plates closely connected with a tight membrane each to other, each plate proximally with well-developed ramus (Fig. 18). Male genitalia (Figs. 14-16). Median lobe of aedeagus long, ventrally bent at an angle lesser than $90^{\circ}$, dorsally slightly curved to right apically, with apical lamella somewhat narrowed before tip, thereupon widened and rounded at tip. Inner sac of aedeagus without chitinized structures. Left paramere conchoid, without transverse apophysis, with apical denticle on ventral margin (Figs 14-15, a). Right paramere broken, but clearly falcate, with apical part shortly attenuate, medial part strongly broadened and a hasp at subbasal position (Figs 14-15, b). Female genitalia (Figs 19-21). Laterotergite subtriangular, with round, protruding apophysis anteriorly and group of 10-12 trichoid setae posteromedially; gonocoxite 1 relatively narrow, elongate, nearly twice as long as gonocoxite 2, with four long trichoid setae on ventral surface; gonocoxite 2 rather wide, about two and a half times longer than wide, with sides narrowed distally, apex widely rounded, two broad ensiform setae, one 

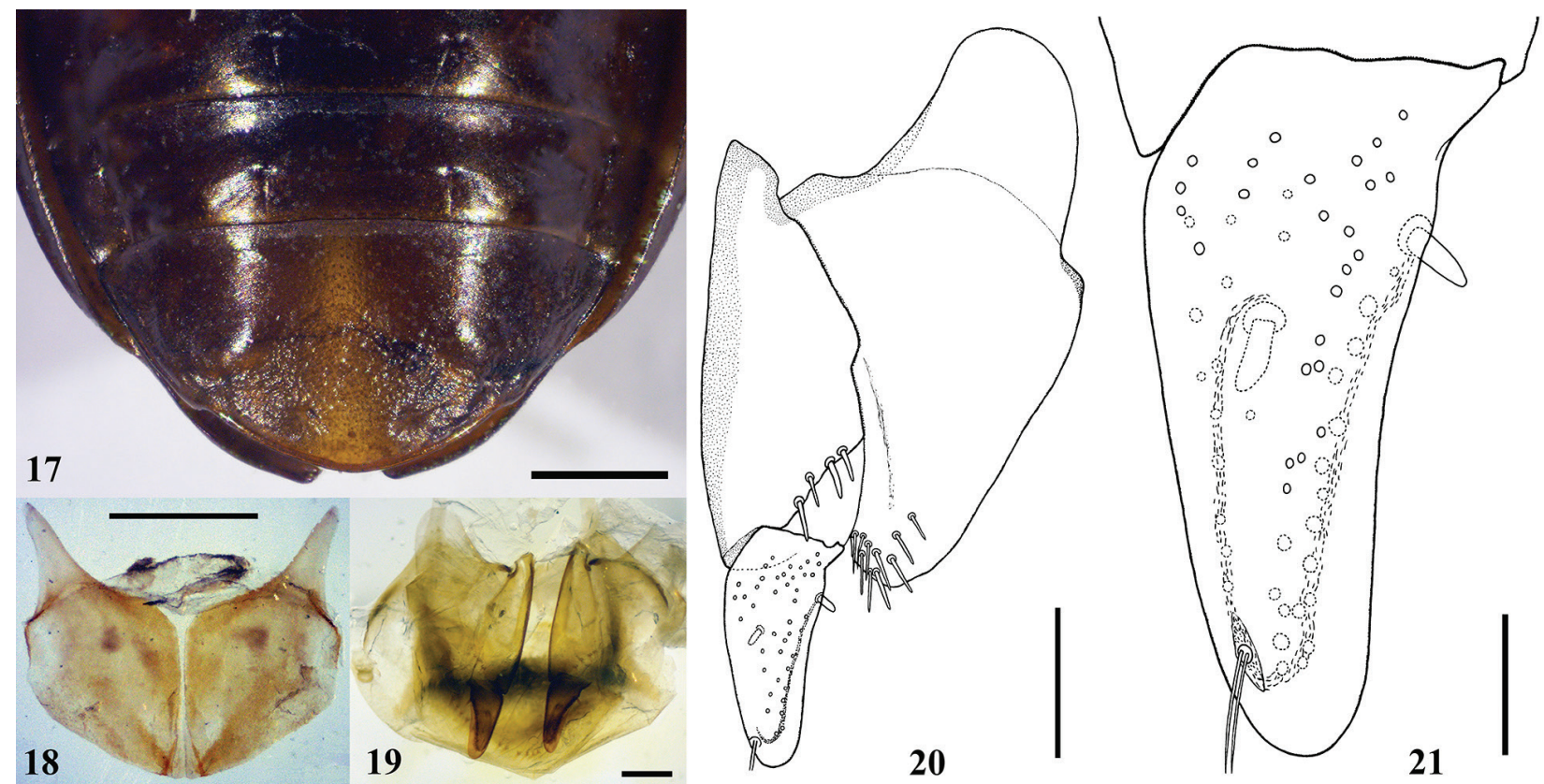

Figures 17-21. Apophylon gen. n. pangu sp. n. from Zhangjiajie national Forest Park, Hunan, China, female paratype. 17 Abdominal sternites 5-6, ventral view; 18 Postabdominal sternite 7, dorsal view; 19 Gonocoxae, ventral view; 20 Left gonocoxa and left laterotergite, ventral view; 21 Left gonocoxite 2, ventral view. Scale lines: $1 \mathrm{~mm}$ (Figs 17-18); 0.3 mm (Figs 19-20); $0.1 \mathrm{~mm}$ (Fig. 21).

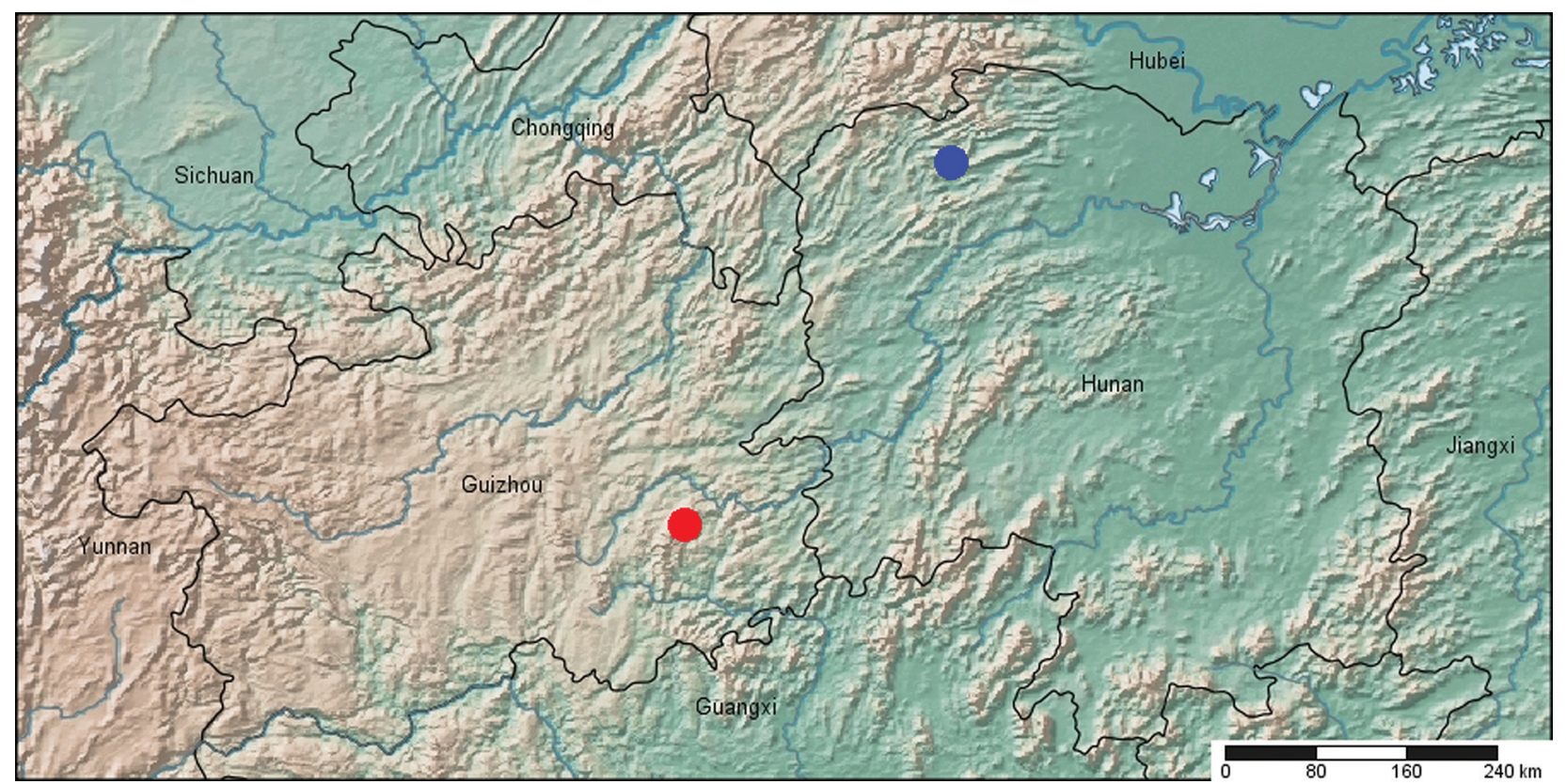

Figure 22. Map of the provinces of Guizhou and Hunan with localities (red circe type locality of Apophylon gen. n. schillhammeri sp. n.; blue circle type locality of Apophylon gen. n. pangu sp. n.).

dorsomedial and one dorsolateral, ensiform setae slightly shorther than both nematiform setae and trichoid setae of laterotergite and basal gonocoxite, preapical sensory furrow on ventral surface, with furrow peg bearing two very long and thin nematiform setae, and numerous pit pegs on both surfaces (some larger pit pegs more or less regularly arranged along dorsal edge spreading between two ensiform setae).
Etymology. A noun in the nominative for the Chinese deity Pangu or Pan $\mathrm{Gu}$, who is the first living being and the creator of everything in some versions of Chinese mythology.

Type locality and habitat. The field notebook of Harald Schillhammer (personal communication) indicates the following data about the site and time when the type series of $A$. pangu sp. n. was collected: "Zhangjiajie For- 
est National Park, Suoxiyu Nature Reserve, Wulingyuan section (ca. $30 \mathrm{~km} \mathrm{~N}$ Zhangjiajie City); ca. 2 km downstream of Shuiraosimen; small branch of Jinbian Xi, ca. 1-2 m wide, slowly flowing, with riffle areas and pools; 30.X.1993; leg. Schönmann, Schillhammer \& Ji; [4]”. According to Harald Schillhammer (personal communication), the altitude of the site of collecting is ca. 450 $\mathrm{m}$ and approximate GPS coordinates are $29^{\circ} 21.10^{\prime} \mathrm{N}$, $110^{\circ} 29.06^{\prime} \mathrm{E}$. This site is located near Wulingyuan Town, Wulingyuan District, Zhangjiajie Prefecture, north-western part of Hunan Province, China (Fig. 22).

The rivers of Shuiraosimen and Jin Bian Xi flow into the basin of the Lishui River (or Li River), which is one of the main tributaries of Yangtze River in Hunan. Most probably, as its congener, the species is a hygrophilous lowland dweller that lives adjacent to water.

Note. We note that the description of $A$. pangu is based on teneral specimens. Hence, some observations, such as micropunctation, microsculpture, color and luster, structure of internal sac of aedeagus, may differ in fully sclerotized adults.

\section{Discussion}

The two new species exhibit several peculiar characters which are described below according to their phylogenetic significance. At least the last two of them are suggested to be apomorphic.

1) Left paramere without transverse apophysis, with apical denticle on ventral margin.

According to Bousquet (1999), all the genera from the "pterostichite complex" have, or have lost as a second adaptation, a left paramere with transverse apophysis. Based on derived larval characters shared, this author also recognized a "molopite complex" of genera within the "pterostichite complex". He stated that, among the genera of the "molopite complex", only Abax, Molops and Percus possess a left paramere without transverse apophysis. Based on the aforementioned derived character shared by the species of the last three genera, Bousquet considered the lack of transverse apophysis on the left paramere as a result of reversal rather than in a plesiomorphic state. We compared the left parameres of species from Abax and Molops with that of the new species, and established that the European taxa exhibit a rather modified conchoid type of paramere: more elongate, with a more prominent basal bulge on external face, without apical denticle on the ventral margin. The left parameres in the two species of Apophylon gen. n. represents a distinct, maybe archetypal conchoid pattern, i.e. with less prominent basal bulge on the external face and a clear apical denticle on ventral margin (the latter state occurs also in species from subtribe Sphodrina Laporte, 1834, see Casale 1988: 383: Fig. 541, 409: Fig. 581), compared with the left parameres in most Pterostichini. On this ground, taking into account also two characters states shared by the species of Abax,
Molops and Percus, i.e. mesotrochanter without seta and highly reduced right paramere, we exclude a relationship between the genera of the "molopite complex" and the new genus from China.

2) Right paramere falcate, with styloid apex, medial part broadened and hasp situated subbasaly on the internal face.

This specific shape of right paramere is unknown among the Holarctic and Oriental Pterostichini, though a few species are somewhat similar. Pterostichus (Neohaptoderus) kleinfeldianus Sciaky \& Wrase, 1997 (Sciaky and Wrase 1997: 1124, Fig 4c) has a right paramere similarly widened medially, but with a hasp situated medially and a basal part different in form. The medial position of the hasp in most Pterostichus Bonelli, 1810 species is presumably the result of a reduction of the apical part of the paramere, while the basal situation of the hasp is a probable plesiomorphic condition. Pterostichus (Petrophilus) melanarius (Illiger, 1798) also possesses a similarly curved right paramere, but it is less broadened medially and thinner apically. These two examples show a convergence in the shape of the right paramere, since the species of this genus differ greatly in other traits (median lobe of aedeagus with ostium situated on the left site, left paramere with transverse apophysis, etc.) that are completely different from those in the new species. Completely different shaped is the right paramere in the species from the large Holarctic genus Poecilus Bonelli, 1810, which is short, not elongate apically (cfr. Jeannel 1942, Fig. 256 a, c, e, g and Fig. 257 a, b, d, e f, i).

It is worth noting that the form of the right paramere of Apophylon gen. n. greatly resembles right parameres of some species belonging to Sphodrina (see Casale 1988: 188: Fig. 196, 311: Fig. 438).

3) Median lobe of aedeagus with ostium situated on the dorsal side.

The dorsal position of the ostium is hypothesized as the plesiomorphic state for pterostichines (Bousquet 1999: 33) in contrast with the hypothesized apomorphic condition of having the ostium displaced on left side, as in many presumably more derived groups of Pterostichus. Related to the huge genus Pterostichus, there are several pterostichine genera with the aedeagus with a dorsal ostium; e.g. Gastrellarius Casey, 1918, Stereocerus Kirby, 1837, and the monotypic Aristochroodes Marcilhac, 1993. However, the species from the first two genera possess a left paramere with transverse apophysis. Aristochroodes reginae Marcilhac, 1993 has differently shaped right paramere, heterodynamic elytral striation, and discal setiferous punctures in interval 3 (Sciaky 1996).

Moore (1965) and Sciaky (1994) discussed the position of the ostium in reference to the Pterostichini and noted that it is not an "absolute" feature as Jeannel (1942) stated. The value of this feature should be carefully assessed in the Pterostichini and always in the context of a set of important characters, though it is useful to delimit natural phyletic groups. For example, a left-sided 
ostium is observed in two not related norther hemisphere clades, the small Nearctic genus Lophoglossus Le Conte, 1852 and a huge cluster of subgenera of Pterostichus (Bousquet 1999: 39, Will 1999, Sasakawa and Kubota 2007: 102, Fig. 1). Each of these two groups is suggested monophyletic. Likewise, a distinct right-sided ostium has appeared at least twice independently in two lines of tribe. Once Moore (1965: 2) announced this state for the Australasian Trichosternus series of genera (now the Omalosoma series, cfr. Will 2006a), and secondly, Sciaky (1994) noticed it for the East Asian genus Straneostichus Sciaky, 1994. Phylogenetically, these two groups have no direct relationship with each other, since the former is Gondwanaland ancestry, and the latter belongs to the Laurasian "pterostichite complex" (see above).

4) Metatarsomeres 1-2 (and sometimes metatarsomere 3) setose on medioventral surface, in addition to the lateroventral setae.

We did not find this feature in the Pterostichini examined, except for two genera of the Mediterranean subtribe Euchroina and a single species of "Trigonotomini". All examined species of Orthomus Chaudoir, 1838, and the only species of Parorthomus Guéorguiev, Wrase, Farkač, 2014 possess mesotarsomere 1 and metatarsomeres 1-2 setose on ventral surface beside the lateroventral setae. Trigonotoma lewisii Bates, 1873, also possesses this character and its distribution is like in Orthomus, while other two species of "Trigonotomi", Lesticus serraticollis (Chaudoir, 1868) and Lesticus beroni Dubault, Lassale, Roux, 2012, do not exhibit this character.

This feature is widespread among taxa of the tribe Platynini Bonelli, 1810, a group which is not closely related to the Pterostichini. Barr (1973) noted this feature for the monotypic genus Speocolpodes Barr, 1973 from Guatemala, and we observed it in different phyletic lineages, as Mexisphodrus profundus Barr, 1966 from Mexico; Platynus fracrtilinea (Darlington, 1934) and P. biramosus (Darlington, 1939) from the Caribbean; Altagonum sphodrum Darlington, 1952 and Notagonum altum ibele Darlington, 1952 from New Guinea. Some species of the Sphodrini Laporte, 1834, among them Laemostenus oblongus s.l. (Dejean, 1828), L. cavicola (Schaum, 1858), L. plasoni s.1. (Reitter, 1885), and L. derventicus B. Guéorguiev, 2003, possess the first two segments of the mesotarsomes and mesotarsomeres setose medioventrally. However, this condition in the last taxa is depending on the pubescence on the dorsal surface of the tarsomeres (a generic feature for Laemostenus Bonelli, 1810). Actually, the disposition and density of the medioventral setae of the tasomeres in taxa from different carabid tribes suppose this character state evolved independently in different carabid tribes.

5) Meso- and metatarsomeres 1-4 with two dorsolateral grooves divergent distally.

This condition occurs in the two species of Apophylon gen. n. and seems to be an autapomorphy in regard to Pterostichini. Many Eurasian pterostichines that we have examined possess a groove only on the external side of metatarsomeres $1-3$ or $1-4$. Usually a groove is wanting on the inner side of the metatarsomeres. However, some taxa, among them the Western Mediterranean species Poecilus purpurascens s.l. (Dejean, 1828), P. decipiens s.l. Waltl, 1835 and $P$. pantanellii (A. Fiori, 1903), from the subgenera Carenostylus Chaudoir, 1838, Parapedius Seidlitz, 1887 and Metapedius A. Fiori, 1903 of genus Poecilus, respectively, possess nearly the same character state as that observed in the new genus. Interestingly, this condition is not present in species from the remaining subgenera of Poecilus, so it may be a mark of close relationships between the aforementioned three subgenera. On the other hand, it is not indication for relation between the last and the new genus for reasons below discussed.

Six Palearctic species of Argutor Dejean, 1821 (Bousquet 2004: 648) also possess a groove on the inner side of meso- and metatarsomeres 1-5. Moreover, the same species of Argutor have a dorsal groove on tarsomeres $1-5$ in all legs. Bousquet (ibid.) suggested that the last state is: "unusual in the genus Pterostichus and is probably apomorphic. It suggests that these species form a monophyletic group within the subgenus". There are some striking differences between the tarsal grooves in Argutor and those in Apophylon gen. n., thus this does not provide any evidence for a relationship between these taxa. The meso- and metatarsal grooves in Argutor are: a/ three; b/ lateral grooves are situated each to other at $180^{\circ}$ regarding the tarsal axis, so they are parallel. The grooves in Apophylon are: a/ only two; b/ situated laterally on the dorsal surface; $d$ / convergent towards the base of each tarsal segment and divergent towards its apex. In addition, a dorsal groove is absent on the tarsomeres in the new species.

According to Moore (1965), the Australian species of Loxandrus Leconte, 1852, and Cerabilia Laporte de Castelnau, 1867 (=Feronista Moore, 1965), genera of tribe Abacetini Chaudoir, 1873, as well as the New Zealand Aulacopodus Britton, 1949, a genus currently positioned within the "Notonomus series" (Will 2006b), have mesoand metatarsomeres sulcate on each side. Allen and Ball (1979: 491) observed the same character state in many of the Mexican taxa from the subtribe Loxandrina Erwin and Sims, 1984 (tribe Abacetini). As we have not seen material from the three genera, we cannot compare the states of these genera and the new genus. However, it is evident that similar character states arose independently in different phyletic lines, thus we treat the character in question as an autapomorphy in Apophylon gen. n.

6) Elytral striae with shining isodiametric microreticulation, in contrast to less shining, transverse-mesh reticulation on elytral intervals.

This pattern and distribution of the microreticulation on the tegument is unknown to us and it is likely a result of a microevolution peculiar only to this lineage.

The lack of knowledge about both the female genital tract and the larval characters prevent us from making 
more precise conclusions about the systematic position of the new genus. There are only a few facts that might be interpreted with certainty. The lack of transverse apophysis on the left paramere in the new species is a plesiomorphic character state rather than apomorphic (Bousquet 1999: $33,35)$, taking into consideration that it is joined to an aedeagus with dorsal ostium and to a rather plesiomorphic right paramere, with a styloid apex. Therefore, we propose that the new genus should be placed as incertae sedis within Pterostichini, since it does not show any character states that we consider as shared and derived with any of the following: ("pterostichite complex", incl. the "molopite complex", sensu Bousquet 1999: 37) + ("myadines" + Stereocerus Kirby, 1837, sensu Bousquet 1999: 85 and Bousquet 2012: 50-51) + ("Trigonotomi", sensu Dubault et al. 2008 and Will and Kavanaugh 2012). Out of this grouping, the position of the new genus is obscure.

A close affinity between the new genus from China and the genus Poecilus is unlikely because of the lack of the parascutelar striola and seta on the metatrochanter in the former (both features present in the latter), as well as for the lack of medioventral pubescence on the metatarsomeres 1-3 and the shallow frontal furrows on the head in the latter (both features differently stated in the former). In addition, the taxa of Poecilus s.str. have antennomeres $1-3$ or at least some of them carinate medially; this state is not present in the genus herewith described.

At the moment there is no solid evidence to bring Apophylon gen. n. closer to any of the Gondwanaland branches of the Pterostichini. The new genus is distinct from the genera of subtribe Euchroina (sensu Will 2006c, Guéorguiev et al. 2014; contrasting characters for Euchroina in parentheses) in: right paramere elongate styloid (right paramere reduced, peg-like); lacking parascutellar stria (parascutellar stria present in most taxa); sternites 4-6 without transverse sulci (sternites 4-6 with transverse sulci in most taxa). However, the last two groups share the following significant character states which deserve further consideration to decide if reliable evidence for a relationship between them exists: 1/ large and prominent eyes compared to the size of the head; 2/ well-impressed frontal furrows of head, not or hardly attaining the level of anterior supra-orbital punctures; 3 / submentum without lateral setae; 4/ metacoxa with arcuate anterior marginal sulcus; $5 /$ metatrochanter without seta; $6 /$ tarsomere 5 in all legs setose beneath; and $7 /$ median lobe of aedeagus with dorsal ostium.

Further, there are some important similarities which are worth mentioning between the genus from Guizhou and Hunan and several other pterostichine genera from the Australasian and American continents. The most striking morphological resemblance that we found is with the American Hybothecus Chaudoir, 1874, realizing that it could be partly due to the detailed generic characteristics given by Bousquet (1999: 51-53, Fig. 33). This is due to a lack of detailed characteristics for many pterostichine groups. Except the three characters of the male genitalia (see points 1-3), Hybothecus and Apophylon gen. n. share: 1/ mentum tooth emarginate at apex; $2 /$ lateral setae of submentum absent; 3/ basal impression of pronotum single (from each side) and linear; 4/ elytral striae impressed, impunctate; 5/ no parascutellar striola; 6/ no discal punctures in interval $3 ; 7 /$ apicolateral plica distinct; 8/ seta of mesotrochanter present; 9/ seta of metatrochanter absent; 10/ metatarsomeres 1-3 pubescent ventrally; and 11/ gonocoxite 2 elongate, with nematiform setae.

Some Australian genera (Rhytisternus Chaudoir, 1865, Rhytiferonia Darlington, 1962, Liopasa Tschitschérine, 1901, and Cratogaster Blanchard, 1843, Moore 1965, Baehr 2001), the New Caledonian Platysmodes Fauvel, 1903, and Abacophrastus Will, 2011 (Will 2011a), that are currently arranged within at least three different phyletic lines (Will 2006d), as well as the Chilean Chaetauchenium Tschitschérine, 1900 (Will 2011b), share with the new genus: $1 /$ median lobe of aedeagus with dorsal ostium; 2/ left paramere primitively conchoid, with an apical denticle on the ventral margin; 3 / right paramere falcate, with styloid apex, medial part broadened and hasp situated subbasaly on the internal face; 4/ mentum tooth weakly emarginate; 5/ elytron without both parascutellar striola (present in the New Caledonian genera, present or lacking in the Chilean genus) and setiferous punctures in interval 3 (present or lacking in the Chilean genus). As stated above, each of the first three character states are plesiomorphic (see points 1-3), and therefore cannot be used as an indication of close relationships. In spite of this, we think that these characters taken together, in view of their phyletic weight, could be important in the search for an older affinity and a further investigation based on substantial character analysis could be productive.

At the present status of knowledge, it is impossible to propose what may be the adelphotaxon of Apophylon gen. n. and thereby determine its close relatives. Therefore, we treat this genus as incertae sedis within the Pterostichini. On the other hand, it seems that the genus may be the only relict of an early taxonomic branch of the "Angarian" (Asiatic-European) provenance. Whether or not this branch has other extant descendants is not clear. Finally, we note that its systematic position cannot be examined in more depth until a major phylogenetic analysis can be undertaken either by a more detailed morphological analysis, by a molecular analysis, or desirably, by both.

\section{Acknowledgements}

We thank Harald Schillhammer (NMW) for providing us with precise descriptions of sites and habitats where he collected the new species, Kipling Will (Essig Museum of Entomology, University of California, Berkeley, United States of America) for the interesting discussion regarding the relations of the new taxa with southern hemisphere Pterostichini, and David Baker (Danyang, South Korea) for kindly helping us checking the English style 
of a preliminary draft of this paper. A previous draft of the work was reviewed by Kipling Will and James Liebherr (Cornell University, Ithaca, United States of America). We are very grateful them for the many thoughtful critical comments about both style and content. The first author thanks Heinrich Schönmann (NMW) and again Harald Schillhammer (NMW) for their help during his visits in NMW and for the loans of material. SYNTHESYS, the European Union-funded Integrated Infrastructure Initiative grant under FP7 provided funding to support the visit of one of us (BG) to NMW (AT-TAF-1470).

\section{References}

Allen, Ball (1980) Synopsis of Mexican taxa of the Loxandrus series (Coleoptera: Carabidae: Pterostichini). Transactions of the American Entomological Society 105: 481-576. http://www.jstor.org/stable/25078248?seq=1\#page_scan_tab_contents

Baehr M (2001) The genus Rhytiferonia Darlington in New Guinea (Carabidae: Pterostichinae). Coleoptera 5: 41-55.

Ball GE, Shpeley D (2013) Western Hemisphere Zuphiini: descriptions of Coarazuphium whiteheadi, new species, and Zuphioides, new genus, and classification of the genera (Coleoptera, Carabidae). ZooKeys 315: 17-54. doi: 10.3897/zookeys.315.5293

Barr TC Jr. (1973) Speocolpodes, a New Genus of Troglobitic Beetles from Guatemala (Coleoptera, Carabidae). Psyche 80(4): 271-276. doi: $10.1155 / 1973 / 83417$

Bousquet Y (1999) Supraspecific classification of the Nearctic Pterostichini (Coleoptera: Carabidae). Fabreries, Supplément 9, 292 pp.

Bousquet Y, Webster RP (2004) Review of the Nearctic species of the Holarctic subgenus Argutor (Coleoptera: Carabidae). The Canadian Entomologist 136: 645-660. doi: 10.4039/n04-030

Bousquet Y (2012) Catalogue of Geadephaga (Coleoptera, Adephaga) of America, north of Mexico. ZooKeys 245: 1-1722. doi: 10.3897/ zookeys. 245.3416

Casale A (1988) Revisione degli Sphodrina (Coleoptera, Carabidae, Sphodrini). Museo Regionale di Scienze Naturali Monografie V, Torino, $1024 \mathrm{pp}$.

Dubault G, Lassalle B, Roux P (2008) Les genres des “Trigonotomi” : Pareuyaptus n. gen. et révision des Euryaptus Bates, 1892 (Coleoptera, Pterostichidae). Bulletin de la Société entomologique de France 113(2): 239-248.

Guéorguiev B, Wrase DW, Farkač J (2014) Revision of the East Mediterranean Orthomus (Coleoptera, Carabidae, Pterostichini), with description of Parorthomus gen. n. socotranus sp. n. from Socotra Island and key to the Old World genera of subtribe Euchroina. ZooKeys 427: 21-57. doi: 10.3897/zookeys.427.7618

Jeannel R (1942) Coléoptères carabiques. Deuxième partie. Faune de France 40. Paul Lechevalier et Fils, Paris, 573-1173. http://www. faunedefrance.org/bibliotheque/docs/R.\%20JEANNEL\%28FdeFr40\%29\%20Carab\%20vol\%202\%20.pdf

Liebherr JK, Will KW (1998) Inferring phylogenetic relationships within the Carabidae (Insecta, Coleoptera) from characters of the female reproductive tract. In: Ball GE, Casale A, Vigna Taglianti A (Eds) Phylogeny and Classification of Caraboidea (Coleoptera: Adephaga).
Atti, Museo Regionali di Scienze Naturali, Torino, 107-170. http:// nature.berkeley.edu/ kipwill/FULLPAPERS/9.pdf

Moore BP (1965) Studies on Australian Carabidae (Coleoptera) 4.- The Pterostichinae. Transactions of the Royal Entomological Society of London 117: 1-32. doi: 10.1111/j.1365-2311.1965.tb00042.x

Sasakawa K, Kubota K (2007) Phylogeny and Genital Evolution of Carabid Beetles in the Genus Pterostichus and Its Allied Genera (Coleoptera: Carabidae) Inferred from Two Nuclear Gene Sequences. Annals of the Entomological Society of America 100: 100-109. http://www.bioone.org/doi/abs/10.1603/0013-8746\%282007\%2910 0\%5B100\%3APAGEOC $\% 5$ D2.0.CO $\% 3$ B2

Sciaky R (1994) Straneostichus gen.n., a new genus and four new species from China (Coleoptera: Carabidae: Pterostichinae). Annalen des Naturhistorischen Museums in Wien Serie B für Botanik und Zoologie 96: 189-198. http://www.landesmuseum.at/pdf_frei_remote/ANNA_96B_0189-0198.pdf

Sciaky R (1996) New taxa and new synonyms among Pterostichinae from Asia (Coleoptera, Carabidae). Entomofauna, Zeitschrift für Entomologie 17(29): 429-439. http://www.landesmuseum.at/pdf_ frei_remote/ENT_17_0429-0440.pdf

Sciaky R, Wrase DW (1997) Twenty-nine new taxa of Pterostichinae from Shaanxi (Coleoptera, Carabidae). Linzer biologische Beiträge 29(2): 1087-1139. http://www.landesmuseum.at/pdf_frei_remote/ LBB_0029_2_1087-1139.pdf

Will KW (1999) Systematics and zoogeography of the genus Lophoglossus Leconte (Coleoptera Carabidae Pterostichini). In: Zamotajlov A, Sciaky R (Eds) Advances in carabidology. Papers dedicated to the memory of Prof. Dr. Oleg L. Kryzhanovskij. MUISO Publishers, Krasnodar, 259-276. http://nature.berkeley.edu/ kipwill/ FULLPAPERS/12.pdf

Will K (2006a) Omalosoma series. Version 07 July 2006 (temporary). http://tolweb.org/Omalosoma_series/51497/2006.07.07 [The Tree of Life Web Project, http://tolweb.org/]

Will K (2006b) Notonomus series. Version 07 July 2006 (temporary). http://tolweb.org/Notonomus_series/51528/2006.07.07 [The Tree of Life Web Project, http://tolweb.org/]

Will K (2006c) Euchroina. Version 21 October 2006 (temporary). http:// tolweb.org/Euchroina/51298/2006.10.21 [The Tree of Life Web Project, http://tolweb.org/]

Will K (2006d) Pterostichini. Version 21 October 2006 (temporary). http://tolweb.org/Pterostichini/102/2006.10.21 [The Tree of Life Web Project, http://tolweb.org/]

Will KW (2011a) Taxonomic review of the Pterostichini and Loxandrini fauna of New Caledonia (Coleoptera, Carabidae). In: Erwin T (Ed.) Proceedings of a symposium honoring the careers of Ross and Joyce Bell and their contributions to scientific work. Burlington, Vermont, 12-15 June 2010. ZooKeys 147: 337-397. doi: 10.3897/ zookeys. 147.1943

Will KW (2011b) Chaetauchenium Tschitchérine, 1900 (Carabidae: Pterostichini) a new species and new status for a lineage from the Valdivian temperate rainforest. Gayana 75(2): 192-197. doi: 10.4067/S0717-65382011000200009

Will K, Kavanaugh DH (2012) A new species of Lesticus Dejean, 1828 (Coleoptera, Carabidae) from the Finisterre Range, Papua New Guinea and a key to the genera of pterostichine-like Harpalinae of New Guinea. ZooKeys 246: 27-37. doi: 10.3897/zookeys.246.4112 